\title{
Design and Execute Media Website for the Sustainable Development Goals
}

\author{
Raheem Abdullah Abood ${ }^{1}$, Dr. Razi J. Al-Azawi ${ }^{2}$ \\ University of Information Technology and Communication, Baghdad, Iraq ${ }^{1}$ \\ University of Technology, Baghdad, Iraq ${ }^{2}$
}

\begin{abstract}
Media has important and influential roles in lives of individuals and communities in modern era, as it can show the negative effects that complicate the development process in developed high society and nations as well. It can also take a role of taking the initiative to put forward plans to raise human knowledge in operations cognitive and behavioural awareness, which in turn leads to the growth of society in general. Now ,the world has a set of problems that surround the environment, resources and energy, man abusing these ground sources all these things make the development of a humanitarian issue urgent and indispensable for many peoples of the world, especially for the developing peoples or least-developed and comes the role of the media in achieving sustainable development through the entrance to the dissemination and adoption of ideas the new and the entrance to prioritize the public about development issues.
\end{abstract}

Keywords: Sustainable development, SDGs, Web Application, Domain Name System (DNS), Uniform Resource Locator (URL).

\section{INTRODUCTION}

Sustainable developing is an action for satisfying man development goals while sustaining the power of instinctual systems to continue to provide the natural resources and ecosystem serves on which the thriftiness and society depends. While the modern concept of sustainable development is derived most strongly from the 1987 Brundtl and Report, it is had intercourse in earlier ideas about sustainable afforest management and 20th century environmental stage business. As the concept developed, it has shifted to focusing more on economic development, social growth and environmental protection for future propagations.

Sustainable development is the forming principle for maintaining finite resource fulnesses necessary to provide for the needs of future propagations of life on the planet. It is a operation that envisions a desirable future state for human societies in which living conditions and resourceuse continue to meet man needs without weakening the "wholeness, stableness and beaut" of natural biotic systems. It was suggested that "the term 'sustainability' should be viewed as humanity's target goal of manecosystem balance (homeostasis), while 'sustainable development' concerns to the holistic approach and temporal appendages that lead us to the resultant of sustainability.

\section{BACKGROUND}

The background of the SDGs can be traced to 1972 when governments met under in Stockholm, Sweden, for the United Nations Conference on the Human Environment, to consider the rights of the human family to a healthy and productive environment.[1] It was not until 1983 that the
United Nations decided to create the World Commission on Environment and Development which defined sustainable development as "meeting the to needs of the present without compromising the ability of future generations meet their own needs." In 1992 the first United Nations Conference on Environment and Development was held in Rio. It was here that the first agenda for Environment and Development was developed and adopted, also known as Agenda [2].

Sustainability can be delimited as the practice of sustaining actions of productiveness indefinitely natural or human created by exchanging resources used with resources of match or bigger evaluate without degrading or endangering natural biotic systems. Sustainable development associations together concern for the acting capacity of natural systems with the social, political, and economic gainsays faced by humanity. Sustainability skill is the study of the concepts of sustainable development and environmental science. There is an extra focus on the present propagations' responsibility to regenerate, maintain and improve planetary resource fulnesses for use by future propagations [4].

\section{WEB APPLICATION}

An application which is gotten to by means of web program over a system is called web application or online application. Every one of the sites are cases of web applications [5]. Web application is composed in a server side scripting dialect like ASP (dynamic server pages).

At the point when client sorts address of site for instance WWW. programming-web. corn, program transmits demand to the web server which has the requiredwebpage 
Vol. 4, Issue 2, February 2017

On web server, web server programming like email gets this demand and procedures it.

The yield produced by web server incorporates just those scripts which can be rendered by web program.

Above process rehashes when client aromas an activity which requires correspondence with server, for example, submitting passage frame or review another page. [7]

\section{- Domain Name System (DNS)}

Domain name system is a distributed computing system that enables to access to Internet resources by using the space names easily than IP addresses, by converting domain names to IP addresses and back, the DNS infrastructure is made up of entities called Name Servers each of which contains information about a small portion of the domain name space, the domain data can provided to any computer by internet [8].

\section{- URL (Uniform Resource Locator)}

A URL is a pointer to roughly bit of data on the web, be it a web text file, a file available via FTP (file transfer protocol), a notice on Usenet, or an email address. The URL allows a universal, reproducible method for finding and accessing information [9] as shown in Fig. 1.

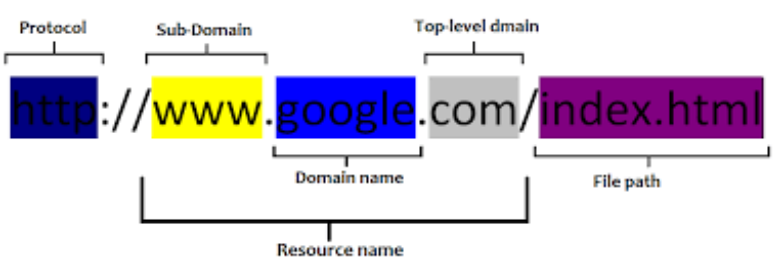

Fig. 1 Uniform Resource Locator

\section{- Web Browser (Client)}

Web program, likewise called a program, which is a product program that solicitations, downloads, and shows Web pages put away on a Web server.

Although programs are basically proposed to utilize the World Wide Web, they can likewise be utilized to get to data gave by web servers in private systems or records in document frameworks. The significant web programs are Firefox, Internet Explorer, Google Chrome, Opera, and Safari, as I would see it Google Chrome is the best since it is tackled numerous issues happened when we utilized distinctive gadgets[10]. A web program: is a product application for recovering, exhibiting, and navigating data assets on the World Wide Web. A data asset is recognized by a Uniform Resource Identifier (URI) and might be a page 'picture, video, or other piece.

CGI (regular portal interface) allude to a detail by which program can speak with a web server [11].

\section{- Web Server}

Web server is in charge of adjusting solicitations for data from web programs. The data can be a record recovered from the server's neighborhood plate, or it can be created by a program called by the server to play out a particular application work [11] as shown in Fig. 2.

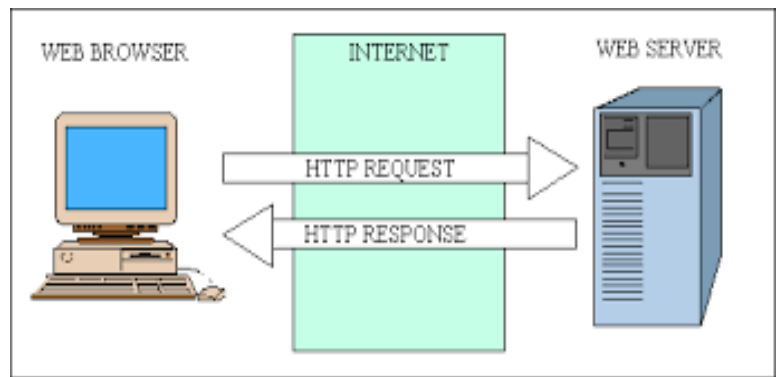

Fig. 2 Web Application

- Client-side programming

- HTML Language

- CSS Language

- Javascript Language

HTML Language (Hyper Text Markup Language)

The Language of Web Pages on the World Wide Web "Ordinary content" encompassed by sectioned labels that advise programs how to show website page Pages end with ".htm" or ".html" [12].

\section{CSS (CASCADING STYLE SHEETS) Language}

CSS of your record indicate above window part. The TITLE of your archive shows up in the exceptionally best line of the client's program. In the event that the client decides to "Bookmark" your page or spare as a "Top choice"; the TITLE is added to the rundown.

The content in your TITLE ought to be as enlightening as could be expected under the circumstances since this is the thing that many web crawlers, on the web, use for ordering your website [13].

\section{Javascript Language}

JavaScript was intended to add intelligence to HTML page JavaScript is a scripting dialect.

A scripting dialect is a lightweight programming dialect. JavaScript is generally installed straightforwardly into HTML pages[14].

JavaScript is a translated dialect (implies that scripts execute without preparatory arrangement).

Everyone can utilize JavaScript without acquiring a permit [15].

\section{SUSTAINABLE DEVELOPMENT GOALS}

Goal 1: End poverty in all its forms everywhere

Goal 2: End hunger, achieve food security and improved nutrition and promote sustainable agriculture

Goal 3: Ensure healthy lives and promote well-being for all at all ages

Goal 4: Ensure inclusive and equitable quality education and promote lifelong learning opportunities for all

Goal 5: Achieve gender equality and empower all women and girls

Goal 6: Ensure availability and sustainable management of water and sanitation for all

Goal 7: Ensure access to affordable, reliable, sustainable and modern energy for all 
Goal 8: Promote sustained, inclusive and sustainable economic growth, full and productive employment and decent work for all

Goal 9: Build resilient infrastructure, promote inclusive and sustainable industrialization and foster innovation

Goal 10: Reduce inequality within and among countries

Goal 11: Make cities and human settlements inclusive, safe, resilient and sustainable

Goal 12: Ensure sustainable consumption and production patterns

Goal 13: Take urgent action to combat climate change and its impacts

Goal 14: Conserve and sustainably use the oceans, seas and marine resources for sustainable development

Goal 15: Protect, restore and promote sustainable use of terrestrial ecosystems, sustainably manage forests, combat desertification, and halt and reverse land degradation and halt biodiversity lossand halt biodiversity loss

Goal 16: Promote peaceful and inclusive societies for sustainable development, provide access to justice for all and build effective, accountable and inclusive institutions at all levels

Goal 17: Strengthen the means of implementation and revitalize theGlobal Partnership for Sustainable Development [1] as shown in Fig. 3.

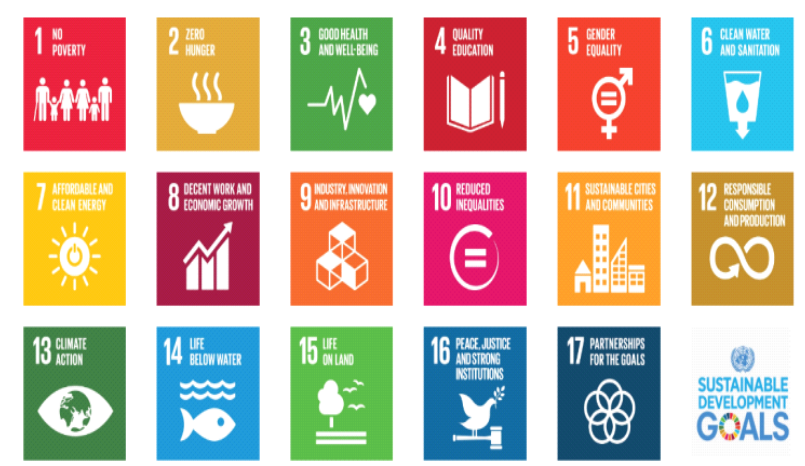

Fig. 3 SDGs

\section{IMPLEMENTATION A MEDIA WEBSITE FOR DSG}

This website has been designed to view and clarify the main sustainable development goals addition to the presentation major news that occur in the world that are interested in this subject. I've designed and implemented my website using programming languages design website.

HTML define the content of web pages. \& CSS to specify the layout of web pages.\& Java script to program the behavior of web pages.

And php language to create Forms like search form and contact us.

The structure of a website pages:-

Header of pages include the name of website and the logo of Informatics Institute for Postgraduate Studies and logo of website as shown in Fig. 4.

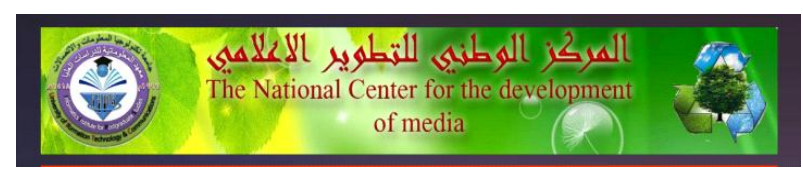

Fig.4 the header of web site

The marque subtitle news about sustainable development. the main bar include five buttons linked to another web pagesas shown in Fig. 5 .

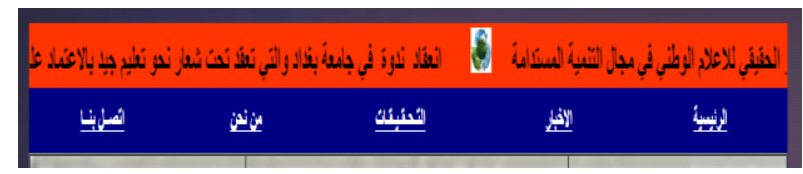

Fig.5 the main bar

Some of the videos that explain the main of sustainable development goals and its own news all over the world.

Include some advertisements in the form of a slide show in an attractive way for some companies for the financing of the site. Footer of web site contain the copyright of the web siteas shown in Fig. 6.

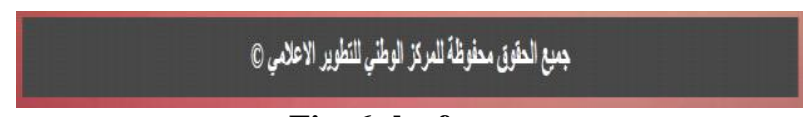

Fig. 6 the footer

The side bar include 10 buttons linked to different web pages in the site search form use to search about any word in the siteas shown in Fig. 7.

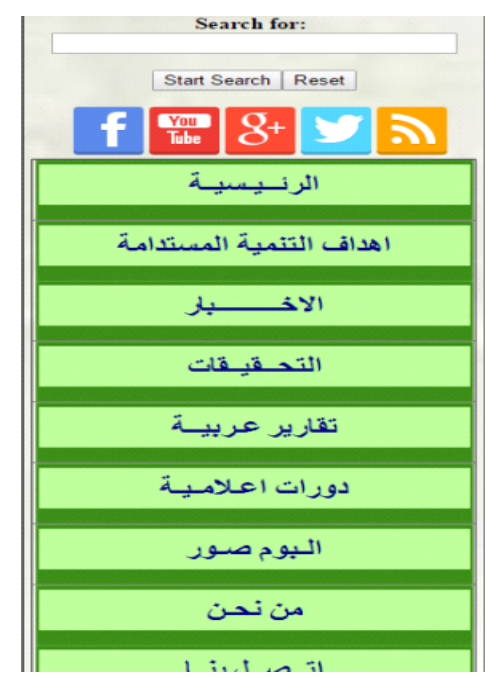

Fig.7 the side bar

Development of the pages: -

There are some video reports about the Sustainable Development Goales .

1. The Sustainable Development Goals: - contain 17 goales pictures everyone have link to the United Nations web site expline the goals.

2. The news: - page news about the SDG view some media like images, video and text.

3. Investigations: - page view some press investigations about SDG using media like video and text to expline 
Vol. 4, Issue 2, February 2017

the Sustainable Development Goals. Arabic reports:page view some reports about meeting and workshops which interest to Sustainable Development Goals.

4. Information sessions: - page views some advertisement about courses for media, the image or some text is hyperlink to the web site that interest the information sessions.

5. photogallary:- contain some images about the Sustainable Development Goals and slide show about beautiful nature.

6. Contact us: - page contain the form can be communicate with the site visitors and to contribute to the development of the site.

7. Thank you for your visit to our site.

\section{CONCLUSION}

The Sustainable Development Goals (SDGs), authoritatively known as transforming our reality: the 2030 Agenda for Sustainable Development is an arrangement of seventeen optimistic "Worldwide Goals" with 169 focuses between them. Led by the United Nations, through a deliberative procedure including its 193 Member States.

In this project used programming languages like HTML \& CSS \& JavaScript to create an informational website publishes the basic concepts of sustainable development and awareness and education in this direction to create a society free of environmental and health problems, especially in developing countries, in addition to all types of multimedia in this website pertaining to sustainable development News.

This venture presented for the sites. Site planned by utilizing many web programming dialects that are HTML, PHP and My/SQL dialects. HTML Hypertext Markup Language (HTML) is a dialect used to make Web pages. Also, second dialect in this venture is PHP; it is a free, open source scripting dialect and is a server side dialect. Also, another dialect in my exploration is CSS utilized for portraying the look and organizing of an archive written in a markup dialect. While regularly used to change the style of website pages and JavaScript was intended to add intelligence to HTML page, JavaScript is a scripting dialect.

\section{ACKNOWLEDGMENT}

I would I would like to thank Dr.Razi J. Al-Azawi for his supervision during the period of the research, encouragement, comments and help, and thanks all those who stand beside me in my study and give me the encouragement to do this research, Family, and supportive friends.

\section{REFERENCES}

[1] UN. "Sustainable Development Goals."United Nations.Last modified Accessed 2016. http://www.un.org/sustainable development/ar/sustainable-development-goals/.
[2] Elameer, AmerSaleem, "The Global Goals for Sustainable Development." Toward good education based on e-learning as one of the global targets for sustainable development, Baghdad, 2016.

[3] UlrichGrober: Deep roots - A conceptual history of "sustainable development" (Nachhaltigkeit), Wissenschaftszentrum Berlin fürSozialforschung, 2007

[4] Bringing human health and wellbeing back into sustainable development. In: IISD Annual Report 2011

[5] MrawanS.Al - Dabbagh, " A Web site Pages Design on The Internet", Dissertation Paper - 2005.

[6] Shane Diffily, "The Website Manager's Handbook", ISBN, 2010.

[7] Irina Dumitrascu, "Building your first dynamic website part-1 :Setting up your site and database connection", Adobe system Incorporated, 2010.

[8] Jennifer Niederst Robbins, "HTML and XHTML", Fourth Edition, Packet publishing Ltd, 2009.

[9] Matthew MacDonald, "Creating a Websie", 3rd Edition, Printed in the United States, O'Reilly Media, Inc., 2011.

[10] Smith, Bud E. Creating Web Pages for Dummies. Ninth ed. New Jersey: Wiley Publishing, Inc.,2009.

[11] Robbins, Jennifer Niederst. Learning Web Design. Forth ed. Sebastopol: O'Reilly Media, Inc., 2012.

[12] Smith, Peter. Professional Website Performance: Optimizing the Front End and Back End. Indiana: John Wiley \& Sons, Inc., 2013.

[13] Duckett, Jon. Html and Css: Design and Build Websites. Fourth ed. Indiana: John Wiley \& Sons, Inc., 2011.

[14] Drouin, Matthew. Web Hosting and Web Site Development: A Guide to Opportunities. First ed. New York: The Rosen Publishing Group,Inc., 2001. 